\title{
EDITORIAL
}

\section{Training in aneurysm surgery}

\author{
Roberto C. Heros
}

Received: 22 June 2009 /Accepted: 22 June 2009 / Published online: 16 July 2009

(C) Springer-Verlag 2009

I have been asked to write an editorial on this paper and comment specifically on the training of residents in aneurysm surgery in the United States.

First of all, I would like to compliment Professor Wester for his remarkable honesty and the candor with which he has analyzed and presented to us his failures in aneurysm surgery. I would like to begin by stating that although Dr. Wester seems to be apologetic and regrets his less than satisfactory training in aneurysm surgery during his residency, in fact, his results have been excellent and at least comparable to those of dedicated, experienced vascular neurosurgeons. Taking the liberty of commenting on my own personal experience, I will acknowledge that I have encountered, unfortunately more frequently than Dr. Wester, just about all of the intraoperative complications that he describes, and my results with aneurysm surgery have indeed been very similar to his. In the overall, Dr. Wester found that he had encountered significant intraoperative technical complications in $6.3 \%$ of his aneurysm patients. In my series of non-giant, anterior circulation aneurysms, I found an incidence of about $5 \%$ of significant intraoperative mishaps. However, my results with giant aneurysms, and particularly with basilar aneurysms (nearly $20 \%$ intraoperative complications), have been considerably worse.

Professor Wester feels that his analysis will be of value mostly to neurosurgeons from the third world who have not had the benefit of an excellent neurosurgical training. Again, he is being unnecessarily humble, and it is clear to me that his careful analysis of intraoperative complications

R. C. Heros $(\bowtie)$

Department of Neurosurgery,

University of Miami School of Medicine,

Miami, FL, USA

e-mail: Rheros@med.miami.edu will benefit even experienced neurosurgeons. It is true that all of the intraoperative complications that he encountered, perhaps with exception of the most unusual case where the clip applier failed to release the clip, have been encountered by every experienced neurosurgeon and have been well described, particularly in specific chapters concerning aneurysm surgery. However, to put them together as a compact article in a scientific journal is of considerable value.

In reference to the way we train residents in aneurysm surgery in the US, the most accurate statement that I can make is that such training varies widely among institutions, as I am sure it does in Europe and elsewhere. I am sure that Dr. Wester's inadequate training in aneurysm surgery is not representative of neurosurgical training in Europe. I personally have had the pleasure of having as cerebrovascular fellows several individuals that had their basic neurosurgical training in Europe, and they certainly were trained at a level comparable to that of our residents when they came to us for their fellowship. Since I cannot speak for the US in general, I will speak from my own experience. Generally, I have followed the formula of "see one, do one and teach one" with the very significant difference that the numbers have not been "one." The number of aneurysm surgeries that a resident needs to "watch" or assist in before he/she can do the dissection and clip the aneurysm personally varies widely from resident to resident. Likewise, there is wide variation both because of intrinsic technical abilities and because of temperament in the ability of a senior resident, or more properly a chief resident, to actually "teach" a younger resident how to operate on a simple aneurysm. Although not always accomplished, my goal has been that by the time the resident completes his/ her training, he/she should be able to clip independently most non-giant anterior circulation aneurysms and should be able to teach a younger resident how to carry out the 
dissection and clipping of "simple" aneurysms, such as small posterior communicating and middle cerebral artery aneurysms. Over the span of my career, as the senior neurovascular surgeon in four different academic institutions, I estimate that by the completion of their residency, each finishing resident has personally done all the critical phases of the dissection and clipping of the aneurysm in an average of 25-40 cases, although some have done far fewer and a few gifted ones have done more. In addition, the most capable residents have been able to take a more junior resident through the critical dissection and clipping of simple aneurysms while
I have been mostly "watching" the operation on the television screen making a comment every now and then and perhaps "readjusting" the clip even though frequently that was unnecessary. I would venture to add that, from data available from our Residency Review Committee, this experience and these numbers are not unusual among the larger teaching centers in the US.

I will finalize by stating that it has given me a great deal of pleasure to read this very personal and forthright bird's eye view of Professor Wester's experience as an aneurysm surgeon. I congratulate him for his honesty and excellent surgical results. 